\title{
Properties of different ethyl alcohol based secondary fluids used for GSHP in Europe and USA
}

\author{
Monika Ignatowicz, Åke Melinder, Björn Palm
}

\begin{abstract}
The extensive use of ground source heat pumps (GSHP) for heating and cooling purposes has made Sweden the European leader in geothermal energy utilization, in terms of the installed capacity, as well as extracted thermal energy. The commercially available etbyl alcohol based fluids in Sweden are distributed as 88 - $95 \mathrm{wt}$-\% etbyl alcohol concentrate, including up to $12 \mathrm{wt- \%}$ of denaturing agents in form of propyl alcohol (8 to $10 \mathrm{wt} \%$ ) and $n$ butyl alcohol (2 wt-\%). In Switzerland the commercial etbyl alcohol products contain 2 vol-\% methyl ethyl ketone and 0.5 vol-\% methyl isobutyl ketone, whereas in Finland commercial products contain up to 1.8 vol-\% methyl ethyl ketone and 2.7 vol-\% methyl isobutyl ketone. In North America the most common denaturing agents for ethyl alcohol based secondary fluid are methyl alcohol (methanol) (3.76-10 wt-\%) and pine needle oil (up to 0.5 vol-\%). The chemical character of these denaturing agents can in different ways affect the thermophysical properties. Thus, the aim of this paper was to investigate the thermophysical properties of different commercially available alcohol blends in Europe and United States. The results showed that the commercial product commonly used in Sweden (EA18 + PA1.6 + BA0.4) has the best thermophysical properties among different ethyl alcohol based products found in Europe when taking into consideration all thermophysical properties. Pure $M A 20$ poses better thermophysical properties than EA18+MA2 and the lowest viscosity among all investigated alcohol blends. MA2O has as well good properties but special care needs to be taken due to bigh toxicity of methyl alcohol. Moreover, EA18+MA2 does not have good thermophysical properties compared to other ethyl alcohol blends and products containing small amounts of propyl and butyl alcohol or ketones are more recommended instead.
\end{abstract}

\section{INTRODUCTION}

Atnics et al., 2016 has reported that the total number of ground source heat pump (GSHP) installed in Europe exceeds 1.7 million units. Sweden among other European countries is the leader in geothermal energy utilization in terms of the installed capacity and extracted thermal energy (Gehlin et al., 2016). It is estimated that there are about 500000 small and 500 large ground source heat pumps (Acuña et al., 2015). According to the statistics there are around two million single-family houses in Sweden and around $20-25 \%$ of these houses are heated by GSHPs. The dominant type of GSHP systems are shallow low temperature systems ranging from 5 to $10 \mathrm{~kW}$ that provide about 23 TWh of heating and cooling. The total installed heating and cooling capacity in Sweden is estimated to be 6.8 GW. The typical Swedish setup consists of one or several vertical borehole heat exchangers (BHE) having a depth between 120 and $300 \mathrm{~m}$ (Gehlin et al., 2016). In many countries the space around the U-pipe in the borehole is filled with grout to prevent water and contaminants migration along the vertical borehole (Gustafsson et al., 2010). Swedish guidelines allow for ungrouted, groundwater filled BHE. Moreover, the market for larger shallow GSHP systems for both residential and non-residential buildings has been expanding over the last years (Gehlin et al., 2016). Ethyl alcohol based secondary fluid is one of the most common secondary fluids in Sweden for GSHP application recommended by the Geological Survey of Sweden (SGU) and the Swedish Environmental Protection Agency due to 
relatively good thermophysical properties and low toxicity (SGU, 2008). Due to the flammability risks ethyl alcohol based secondary fluids are usually not exceeding $30 \mathrm{wt}-\%$, corresponding to the freezing point of $-20.5{ }^{\circ} \mathrm{C}$. European Union regulations strictly define the types and concentrations of denaturing agents added to prevent from drinking ethyl alcohol. The most common type of denaturing agents in Europe are: propyl alcohol (2-propanol, isopropanol, PA), n-butyl alcohol (n-butanol, BA), methyl ethyl ketone (2-butanone, MEK) and methyl isobutyl ketone (4methylpentan-2-one, MIBK) (EUR-Lex, 2013). There are only two approved denaturing agents for ethyl alcohol based secondary fluid in Sweden: propyl alcohol and n-butyl alcohol due to their low toxicity compared to ketones. Both propyl and butyl alcohols occur in nature as the fermentation products and their biodegradation time is up to 28 days. The commercially available ethyl alcohol based secondary fluids in Sweden are normally distributed as $88-95$ wt- $\%$ ethyl alcohol concentrate, including up to $12 \mathrm{wt}-\%$ of denaturing agents but no corrosion inhibitors. The most common type of ethyl alcohol product in Sweden contains $8 \mathrm{wt}-\%$ propyl alcohol and $2 \mathrm{wt}-\% \mathrm{n}$-butyl alcohol. Another less used product on the Swedish market contains $12 \mathrm{wt}-\%$ of denaturing agents $(10 \mathrm{wt}-\%$ propyl alcohol and 2 wt- $\%$ n-butyl alcohol) (Helachem, 2014). In other European countries, like Switzerland and Finland, commercial products containing a mixture of two ketones are used for GSHP application. In Switzerland the commercial ethyl alcohol products contain 2 vol- $\%$ methyl ethyl ketone and 0.5 vol- $\%$ methyl isobutyl ketone (Alcosuisse, 2014), whereas in Finland commercial products contain up to 1.8 vol- $\%$ methyl ethyl ketone and 2.7 vol- $\%$ methyl isobutyl ketone (Altia Plc. 2012). Instead, in North America the most common denaturing agents for ethyl alcohol based secondary fluid are methyl alcohol (methanol) (3.76 - $10 \mathrm{wt}-\%$ ) (Lyondell, 2003) and pine needle oil (up to 0.5 vol- $\%$ ) (Government of Canada, 2016).

The United States continues to lead worldwide in terms of installed geothermal power capacity. GSHPs are being installed at $8 \%$ annual growth rate with 1.4 million units in operation having a typical size of $12 \mathrm{~kW}$. Approximately $60 \%$ of GSHPs units are installed in residential buildings and the remaining $40 \%$ in commercial buildings. The current trend is that most of the new units are being installed in the commercial buildings. It is estimated that about $90 \%$ of GSHP units are closed loop systems (ground-coupled) and the remaining open loop systems (water-source). Within the residential sector, approximately $70 \%$ of the closed loops systems are horizontal BHEs since they are cheaper to install. In the commercial sector the most dominant type $(90 \%$ of GSHP installations) are vertical BHEs due to rather limited space. Geothermal energy is currently supplying $21 \mathrm{TWh}$ per year of heating in the United States. The corresponding installed capacity is $17.5 \mathrm{GW}_{\mathrm{t}}$. It should be noted that most GSHPs are sized for the cooling loads and are generally oversized in terms of heating capacity (Boyd et al., 2015). The most common type of secondary fluids used for GSHP application are propylene glycol (up to 30 wt- $\%$, corresponding to the freezing point of $-13^{\circ} \mathrm{C}$ ), methyl alcohol (up to $20 \mathrm{wt}-\%$, corresponding to the freezing point of $-15^{\circ} \mathrm{C}$ ) and ethyl alcohol (up to $24 \mathrm{wt}-\%$, corresponding to the freezing point of $-14^{\circ} \mathrm{C}$ ) (IGSHPA, 2011). Recently, ethyl alcohol based secondary fluids are becoming more and more popular type of the secondary fluid for GSHP application (Spitler, 2016). The most common denaturing agents for ethyl alcohol based secondary fluids is methyl alcohol (methanol) (3.76 - $10 \mathrm{wt}-\%$ ) (Lyondell, 2003) that is considered very toxic for human even in small concentrations. Nevertheless, other European commercial products containing ketones or propyl and butyl alcohols can be found on American market as well.

Ignatowicz et al., 2014; Ignatowicz et al., 2015; and Ignatowicz et al., 2016 showed that presence of propyl alcohol in ethyl alcohol solution improves the thermophysical properties such as specific heat capacity, thermal conductivity and dynamic viscosity, when added in small concentrations. The chemical character of various denaturing agents and concentrations can in different way affect the thermophysical properties. Moreover no data regarding the methylated ethyl alcohol as secondary fluid has been found. Thus, a comparative study is made to evaluate the properties of different ethyl alcohol and methyl alcohol based commercial products in Europe and the United States.

\section{METHODOLOGY}

Five different ethyl alcohol water based solutions with different denaturing agents used in Europe and the United States for GSHP application were studied. The total alcohol concentration in all samples was set to be 20 wt$\%$. Note that samples containing ketones have higher total concentrations compared to samples with different alcohol based denaturing agents. The measured thermophysical properties (freezing point, density, dynamic viscosity, thermal conductivity and specific heat capacity) for different solutions were compared with three reference fluids (deionized 
water, pure $20 \mathrm{wt}-\%$ ethyl alcohol solution, (EA20) and pure $20 \mathrm{wt}-\%$ methyl alcohol solution, (MA20) to evaluate the measurement errors. Note that commercial glycol products used in Europe and the United States are not investigated in this study due to differences in thermophysical properties. Table 1 summarizes the chemical composition of different ethyl alcohols solutions.

Table 1. Chemical composition of different alcohol samples.

\begin{tabular}{|c|c|c|c|}
\hline Sample & Ethyl alcohol (wt-\%) & Denaturing agent 1 & Denaturing agent 2 \\
\hline EA20 & $20.0(24.47$ vol-\% $\%)$ & 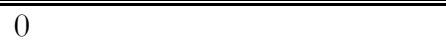 & 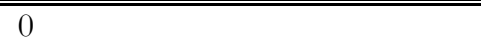 \\
\hline EA18+PA1.6+BA0.4 & $18.0\left(22.07 \mathrm{vol}^{-} \%\right)$ & propyl alcohol (1.6 wt-\%) & n-butyl alcohol $\left(0.4 \mathrm{wt}^{-} \%\right)$ \\
\hline $\mathrm{EA} 17.5+\mathrm{PA} 2+\mathrm{BA} 0.5$ & $17.5(21.47$ vol- $\%)$ & propyl alcohol $(2 \mathrm{wt}-\%)$ & n-butyl alcohol $\left(0.5 \mathrm{wt}^{-} \%\right)$ \\
\hline EA20+MEK1.8+MIBK2.7 & $20.0(24.47$ vol- $\%)$ & methyl ethyl ketone ( 1.8 vol- $\%)$ & methyl isobutyl ketone (2.7 vol-\%) \\
\hline EA20+MEK2+MIBK0.5 & $20.0(24.47$ vol- $\%)$ & methyl ethyl ketone (2 vol- $\%$ ) & methyl isobutyl ketone ( $0.5 \mathrm{vol}-\%)$ \\
\hline EA18+MA2 & $18.0(22.07$ vol- $\%)$ & methyl alcohol (2 wt- $\%)$ & 0 \\
\hline MA20 & 0.0 & methyl alcohol (20 wt- $\%)$ & 0 \\
\hline
\end{tabular}

\section{Freezing Point}

The freezing point temperature was measured using microDSC7 evo from Setaram Instrumentation. Differential Scanning Calorimetry (DSC) method is a thermoanalytical technique in which the difference in the amount of heat required to increase the temperature of sample and reference is measured simultaneously. Both sample and reference are maintained at the same temperature throughout the experiment. First the water sample was tested in order to define the testing parameters, using continuous standard zone mode at four different heating and cooling scanning rates: $0.025 ; 0.05 ; 0.1$ and $0.15 \mathrm{~K} \cdot \mathrm{min}^{-1}$. The difference in results for the three first scanning rates was only $0.01 \mathrm{~K}$, thus, the scanning rate of $0.1 \mathrm{~K} \cdot \mathrm{min}^{-1}$ was chosen. The sample volume was always kept the same $(750 \mu \mathrm{l})$ and each test was repeated twice. The accuracy of temperature measurements for the instrument according to the manufacturer is set to be $\pm 0.1 \mathrm{~K}$. The experimental results were compared with reference values for pure water, 20 wt- $\%$ ethyl alcohol (EA20) and $20 \mathrm{wt}-\%$ methyl alcohol (MA20) solutions (Lide, 1996-97).

\section{Density}

The density measurements were performed using pycnometers. The pycnometer is a glass bottle with a stopper having a capillary tube through it. By knowing the total volume and by measuring the mass of empty as well as of full pycnometer with Mettler Toledo high accuracy analytical balance (accuracy of $+/-0.0001 \mathrm{~g}$ ), it was possible to determine the density of solutions at $20{ }^{\circ} \mathrm{C}$. The accuracy of density measurement at $20{ }^{\circ} \mathrm{C}$ using calibrated pycnometer (volume $25.131 \mathrm{~cm}^{3}$ ) is of $\pm 0.2 \%$. The experimental results were compared with reference values for pure water, $20 \mathrm{wt}-\%$ ethyl alcohol (EA20), and $20 \mathrm{wt}-\%$ methyl alcohol (MA20) solutions found in NIST database, (Lide, 1996-97), (Melinder 2007) and (Melinder 2010). Later, all results can be fitted to a function to extrapolate values in the desired range between $-13^{\circ} \mathrm{C}$ and $30^{\circ} \mathrm{C}$ with the help of literature values.

\section{Dynamic viscosity}

Brookfield rotational viscometer DV-II Pro with special low viscosity adapter (UL-adapter) was used to perform dynamic viscosity measurements in the temperature range between -13 and $30{ }^{\circ} \mathrm{C}$ with the instrument accuracy of $\pm 1 \%$. The working principle of the rotational viscometer is to drive a spindle immersed in the test fluid through a calibrated spring. The viscous drag of the fluid against the spindle is later measured by the spring deflection. All measurements were done using the same UL-adapter and spindle to reduce the uncertainty of measurements. The dynamic viscosity result was obtained as the slope of shear stress versus shear rate function for the range of torque between 10 and $90 \%$. The obtained results for water, $20 \mathrm{wt}-\%$ ethyl alcohol (EA20), and $20 \mathrm{wt}-\%$ methyl alcohol (MA20) were later compared to reference values found in NIST database, (Melinder, 2007) and (Melinder, 2010). 


\section{Thermal conductivity}

Thermal conductivity measurements were performed using Transient Plane Source (TPS) method by means of Hot Disk Thermal Constants Analyser TPS-2500S having the accuracy of $\pm 2 \%$. Hot Disk sensor consisted of an electrically conducting pattern in the shape of a double spiral, which had been etched out of a thin metal foil. This spiral was sandwiched between two thin sheets of Kapton insulating material. When performing a thermal conductivity measurement, the plane Kapton sensor was fitted between two pieces of the sample holder filled with tested sample. By passing an electrical current high enough to increase the temperature of the sensor between a fraction of a degree up to several degrees, and at the same time recording the resistance (temperature) increase as a function of time, the sensor is used both as a heat source and as a dynamic temperature sensor. Kapton sensor 7577 with radius $2.001 \mathrm{~mm}$ was chosen and tests for a given temperature were repeated three times at different measuring time $(2-3 \mathrm{~s})$ and output power $(20-30 \mathrm{~mW})$. All samples had the same volume of $10 \mathrm{ml}$ and were tested in the temperature range between -13 and $30{ }^{\circ} \mathrm{C}$. The measurement results for water, $20 \mathrm{wt}-\%$ ethyl alcohol (EA20), and 20 wt- $\%$ methyl alcohol (MA20) were later compared to reference values found in NIST database, (Melinder, 2007) and (Melinder, 2010).

\section{Specific heat capacity}

The specific heat capacity was measured using a microDSC evo7 from Setaram Instrumentation. The tests were performed in cp continuous mode with heating scanning rate of $0.05 \mathrm{~K} \cdot \mathrm{min}^{-1}$ in temperature range between -15 and $30{ }^{\circ} \mathrm{C}$. Sample volume was always kept constant $(750 \mu \mathrm{l})$. The accuracy of specific heat capacity measurements is \pm 1 $\%$. The obtained results for water, $20 \mathrm{wt}-\%$ ethyl alcohol (EA20), and $20 \mathrm{wt}-\%$ methyl alcohol (MA20) were later compared to reference values found in NIST database, (Melinder, 2007) and (Melinder, 2010).

\section{RESULTS}

The freezing point results for different ethyl alcohol with denaturing agents and methyl alcohol solutions are presented in table 2. As seen, the presence of denaturing agents has affected the freezing point. Note that both samples containing ketones had higher total concentrations compared to samples with different alcohol based denaturing agents. The presence of ketones and methyl alcohol as denaturing agents had the strongest effect on the freezing point and a decrement in the freezing point was observed. EA20+MEK1.8+MIBK2.7 had the highest concentration of ketones and the lowest freezing point of $-13.47{ }^{\circ} \mathrm{C}$ among all samples. The lowest decrement of about $0.4 \mathrm{~K}$ in the freezing point was obtained for EA18+MA2. Both propyl alcohol and n-butyl alcohol had an opposite effect and the increment in freezing point was observed. The highest freezing point of $-10.46{ }^{\circ} \mathrm{C}$ had been measured for EA17.5+PA2+BA0.5, which was having the highest content of propyl and n-butyl alcohols. These results can be explained by the fact that both propyl and n-butyl alcohol water based solutions have higher freezing points compared to pure ethyl alcohol solutions (Lide, 1996-97). Thus, higher concentration of propyl and n-butyl alcohol in solution results in higher freezing point. Note that no reference data for the different ethyl alcohol solutions with denaturing agents were found and the freezing temperatures were compared with pure EA20 solution. Experimental results for pure methyl alcohol solution were in good agreement with the reference (Lide, 1996-97).

Table 2. Freezing point results for different ethyl alcohol solutions.

\begin{tabular}{lccc}
\hline \multicolumn{1}{c}{ Sample } & $\mathbf{T}_{\mathrm{f}} \exp \left({ }^{\circ} \mathbf{C}\right)$ & $\mathbf{T}_{\mathbf{f}}$ ref $\left({ }^{\circ} \mathbf{C}\right)$ & Difference $(\mathbf{K})$ \\
\hline \hline EA20 & -10.92 & -10.92 & 0.00 \\
EA18+PA1.6+BA0.4 & -10.58 & -10.92 & +0.34 \\
EA17.5+PA2+BA0.5 & -10.46 & -10.92 & +0.46 \\
EA20+MEK1.8+MIBK2.7 & -13.47 & -10.92 & -2.55 \\
EA20+MEK2+MIBK0.5 & -12.21 & -10.92 & -1.29 \\
EA18+MA2 & -11.34 & -10.92 & -0.42 \\
MA20 & -15.06 & -15.02 & 0.04 \\
\hline
\end{tabular}


Figure 1, below presents the results of density measurements at $20^{\circ} \mathrm{C}$ for different ethyl alcohol and methyl alcohol based secondary fluids. The difference of around $0.14 \%$ between the experimental and reference value for water was obtained. The experimental result at $20{ }^{\circ} \mathrm{C}$ was slightly higher by up to $0.3 \%$ than the reference value for EA20 found in (Lide, 1997-98), (Melinder, 2007) and (Melinder, 2010), which could be related to the testing method. The experimental result for MA20 was lower by up to $0.3 \%$ than reference values (Lide, 1997-98), (Melinder, 2007) and (Melinder, 2010). As seen, any change in the alcohol concentrations in sample can affect slightly the density due to the fact that both propyl alcohol and n-butyl alcohol have higher densities than ethyl alcohol. The densities of both methyl ethyl ketone as well as methyl isobutyl ketone are lower that the pure ethyl alcohol (Lide, 1997-98). Therefore, both EA20+MEK2+MIBK0.5 and EA20+MEK1.8+MIBK2.7 samples had the lowest densities among all ethyl alcohol based samples. EA18+MA2 had slightly higher density due to presence of methyl alcohol in sample compared to pure EA20.

Figure 2, presents the results of dynamic viscosity measurements. The results obtained for water in full temperature range were higher up to $3 \%$ with reference values (NIST). EA20 and MA20 results were slightly lower than reference values found in (Melinder, 2007) and (Melinder, 2010). As seen, the presence of the denaturing agents in small concentration can significantly decrease the dynamic viscosity in full temperature range. EA18+MA2 had the lowest dynamic viscosity by up to $12 \%$ compared to EA20 due to the fact that methyl alcohol water solutions have lower dynamic viscosity in general. EA18+PA1.6+BA0.4, EA20+MEK2+MIBK0.5 and EA17.5+PA2+BA0.5 had as well lower dynamic viscosity than EA20 at temperature of $-8{ }^{\circ} \mathrm{C}$ by up to $8.4 \%, 7 \%$, and $3.5 \%$ respectively. Only EA20+MEK1.8+MIBK2.7 had the dynamic viscosity higher by up to $2 \%$ than EA20. Thus, the chemical character and concentration of different denaturing agents influences in different way the dynamic viscosity. Similar observations were reported for different blends of ethyl alcohol with propyl alcohol as well as ethyl alcohol with methyl ethyl ketone (Ignatowicz et al., 2014), (Ignatowicz et al., 2015) and (Ignatowicz et al., 2016). Thus, the concentration of denaturing agents in form of alcohols and ketones should be the lowest in order to decrease the dynamic viscosity of ethyl alcohol based secondary fluid.

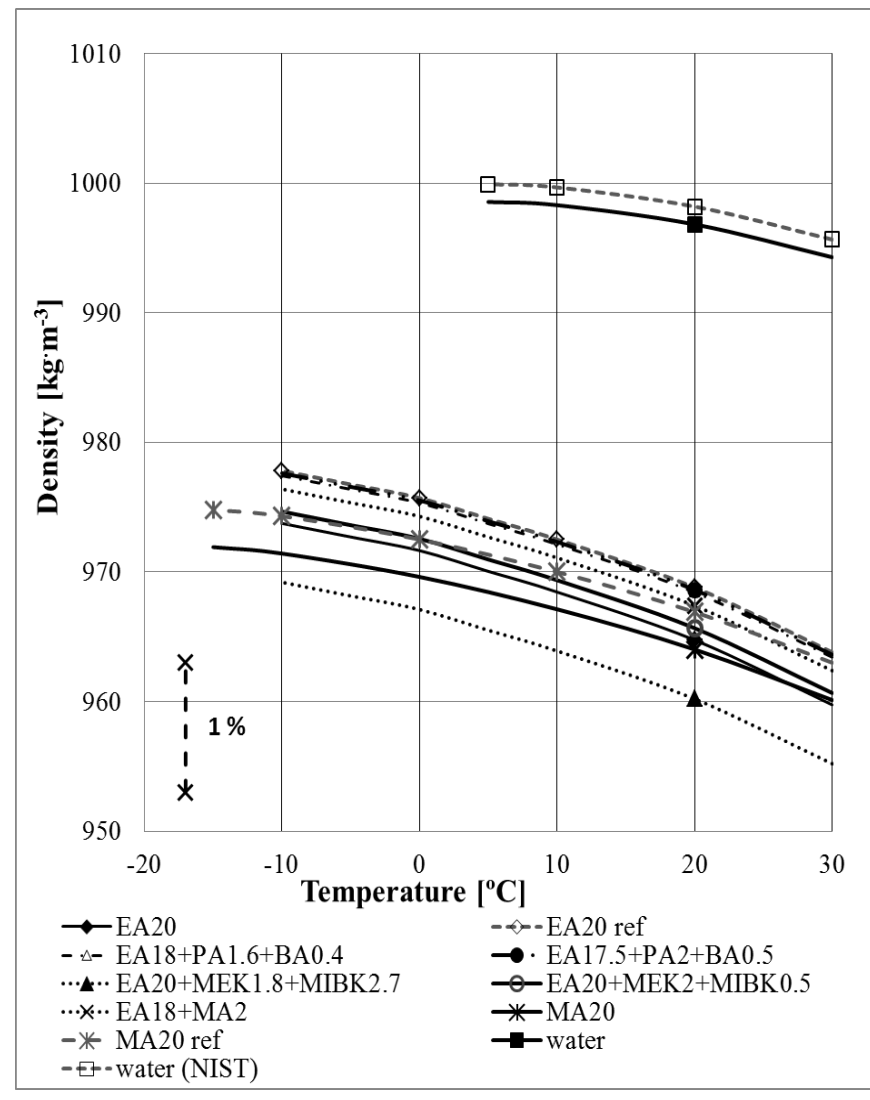

Figure 1Density results.

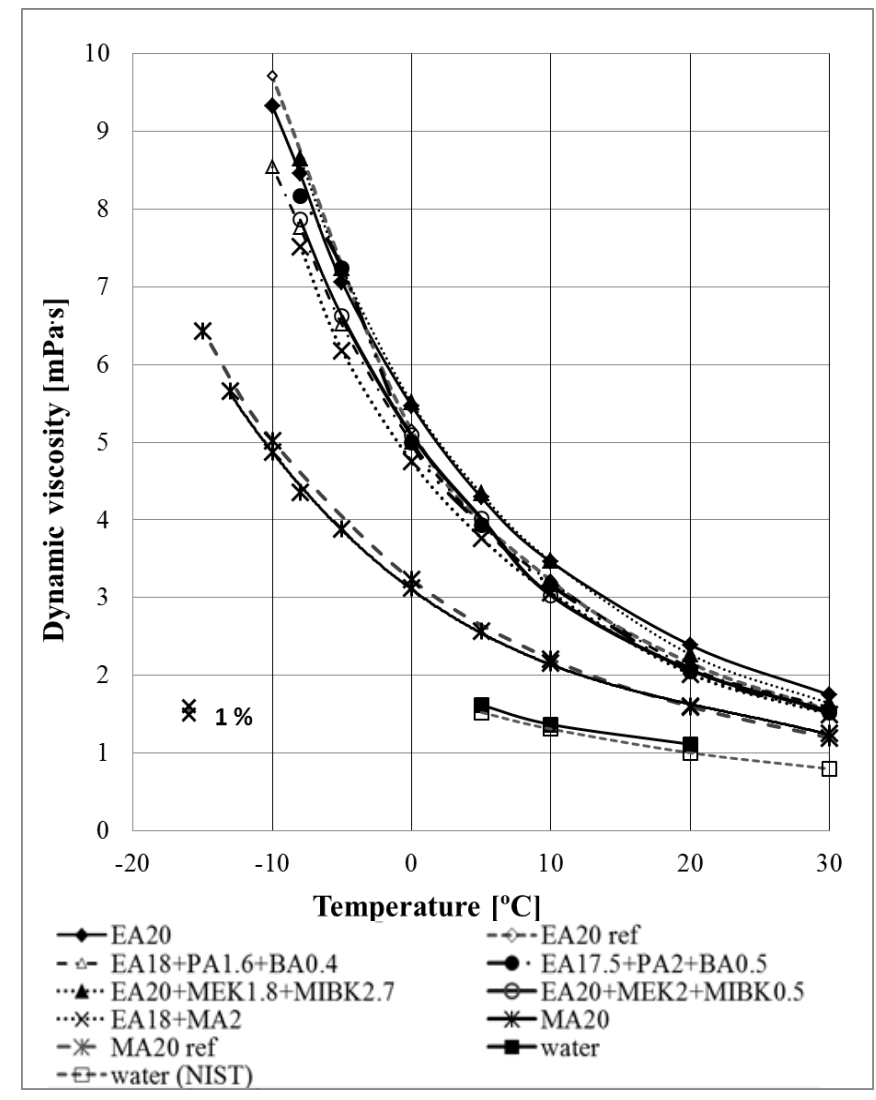

Figure 2 Dynamic viscosity results. 
Figure 3 presents the results of the thermal conductivity measurements. The difference between the experimental results and NIST reference values for water was less than $0.7 \%$, which is significantly below the measurement error of instrument set to be $\pm 2 \%\left(\sim 0.02 \mathrm{~W} \cdot \mathrm{K}^{-1} \cdot \mathrm{m}^{-1}\right)$. It is important to underline that the comparison of different alcohol blends is based on the experimental results obtained for EA20 and MA20 in order to include in the analysis the measurement error. Note that the density and specific heat capacity are input values for post processing of thermal conductivity results since knowledge of the volumetric heat capacity decreases the measurement error below $2 \%$. Higher values of specific heat capacity for EA20 could explain the steeper slope of curve compared to the reference data found in (Melinder 2007) and (Melinder 2010). As seen, only EA18+PA1.6+BA0.4 had higher thermal conductivity by up to $2 \%$ at temperature of $-8{ }^{\circ} \mathrm{C}$ than EA20. Moreover, EA17.5+PA2+BA0.5 had lower thermal conductivity values by up to $2.5 \%$ at temperature of $-8{ }^{\circ} \mathrm{C}$ and $6 \%$ at temperature of $5{ }^{\circ} \mathrm{C}$. Thus, small changes in different alcohol concentration can affect thermal conductivity in a different way. Previous results (Henry and Ignatowicz, 2014) showed that n-butyl alcohol only at small concentrations can increase the thermal conductivity and propyl alcohol at same concentration is giving around $2 \%$ higher values. Thus, small changes in concentrations of three alcohols, especially ethyl and propyl alcohol, can affect the slope of obtained curve and explain the difference in slopes for EA17.5+PA2+BA0.5 and EA18+PA1.6+BA0.4 curves. Moreover, too high concentration of n-butyl alcohol $(1.25 \mathrm{wt}-\%)$ in water seems to decrease the thermal conductivity by up to $8 \%$ (Bertolini et al., 1990). Higher concentration of n-butyl alcohol makes the curve flatter at very low and high temperatures and its effect is becoming stronger at higher concentrations. The presence of denaturing agents in form of ketones had a negative effect on the thermal conductivity in full temperature range. EA20+MEK2+MIBK0.5 had the thermal conductivity values lower by up to $3 \%$ at temperature of $-8{ }^{\circ} \mathrm{C}$ and $8 \%$ at temperature of $5{ }^{\circ} \mathrm{C}$.

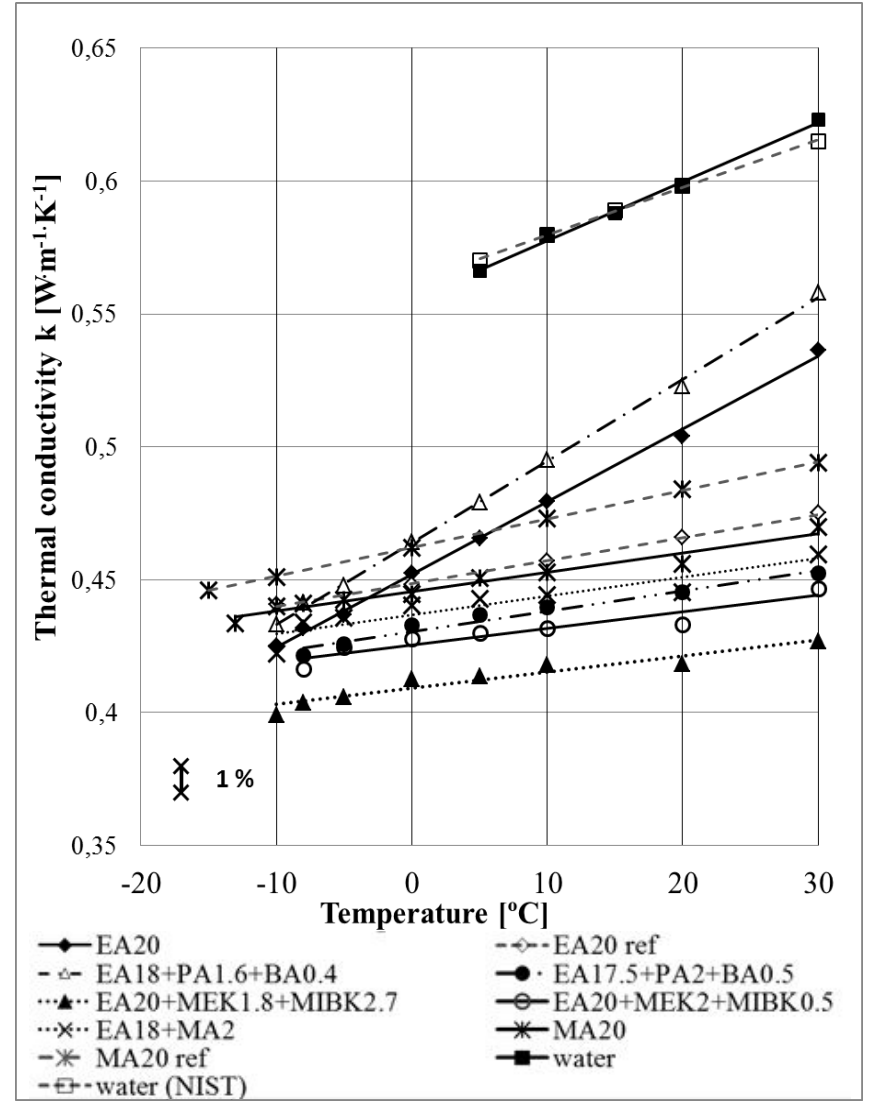

Figure 3 Thermal conductivity results.

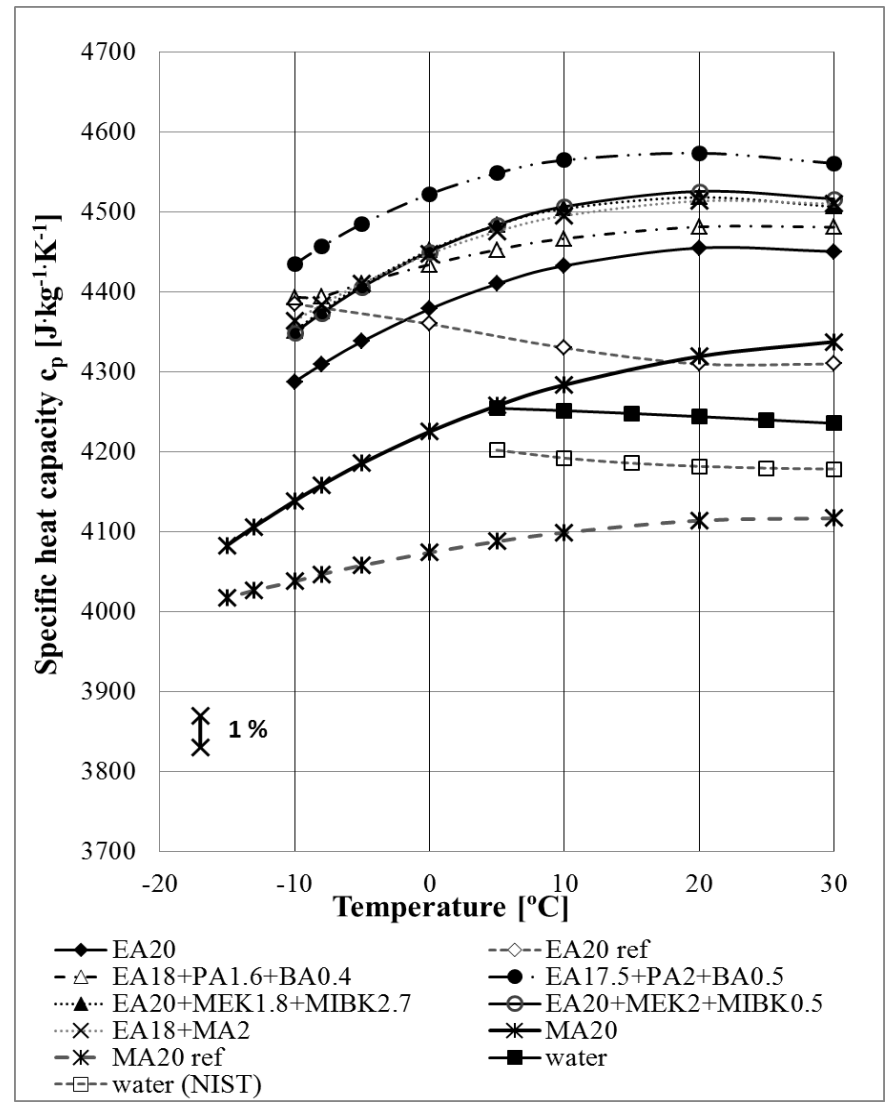

Figure 4 Specific heat capacity results. 
Similar observation was made for EA20+MEK1.8+MIBK2.7 and values lower by up to $7 \%$ at temperature of $-8{ }^{\circ} \mathrm{C}$ and $13 \%$ at temperature of $5{ }^{\circ} \mathrm{C}$ were observed. Thus, the type and concentration of denaturing agent can affect the thermal conductivity and the slope of curve in different ways. MA20 results were lower by up to $1 \%$ at temperature of $-13{ }^{\circ} \mathrm{C}$ and $3 \%$ at temperature of $30^{\circ} \mathrm{C}$ compared to reference values found in (Melinder 2007) and (Melinder 2010), which could be explained again by slightly higher values of volumetric heat capacity used for post processing. EA18+MA2 had lower thermal conductivity by up to $0.2 \%$ at temperature of $-10{ }^{\circ} \mathrm{C}$ and $15 \%$ at temperature of 30 ${ }^{\circ} \mathrm{C}$ compared to pure EA20. Moreover, EA18+MA2 sample had almost same thermal conductivity results compared to reference EA20 data.

Figure 4, shows the results of the specific heat capacity measurements. The experimental results for water were up to $1.5 \%$ higher than NIST references values whereas the accuracy of instrument is set to be $\pm 1 \%(\sim 10 \mathrm{~J} \cdot \mathrm{kg}$ $\left.{ }^{-1} \cdot \mathrm{K}^{-1}\right)$. The standard deviation for five tests for water was $24 \mathrm{~J} \cdot \mathrm{k}^{-1} \cdot \mathrm{K}^{-1}$ and higher measurement error for water could be explained by the small sample volume of $750 \mu$ l. Thus, EA20 and MA20 samples were used as the benchmark so that all measurement errors are considered. Recent results for EA20 solutions, showing a different tendency or slope than some literature values, were reported in (Ignatowicz et al., 2014), (Ignatowicz et al., 2015) and (Ignatowicz et al., 2016). EA17.5+PA2+BA0.5 had the highest specific heat capacity by up to $2.5 \%$ than EA20 and by up to $1.5 \%$ higher than EA18+PA1.6+BA0.4. EA20+MEK2+MIBK0.5 and EA20+MEK1.8+MIBK2.7 showed very similar results and gave by up to $1.5 \%$ higher specific heat capacity than EA20. EA18+MA2 had higher specific heat capacity by up to $1.2 \%$ instead. EA18+PA1.6+BA0.4 had higher specific heat capacity only in temperature range between -10 and $0{ }^{\circ} \mathrm{C}$ (due to the small concentration of n-butyl alcohol) than both samples containing ketones and EA18+MA2. Moreover, measurement results for MA20 were lower by up to $3 \%$ at temperature of $-13{ }^{\circ} \mathrm{C}$ and $5 \%$ at temperature of $30^{\circ} \mathrm{C}$ compared to reference values found in (Melinder 2007) and (Melinder 2010). The difference in results for MA20 could be explained by the fact that the testing method was different and more sensitive DSC instruments with lower scanning rates are available nowadays. It seems that all ethyl alcohol samples with denaturing agents (ketones as well as different alcohols) seem to have higher specific heat capacity than pure ethyl alcohol solution. This phenomenon could be explained by the types of hydrogen bonds between alcohols and water as well as uniqueness of the binary, tertiary and quaternary systems (Peeters and Leroy, 1994) but research studies still continues to understand more the nature of interactions between alcohol molecules in water. The thermophysical properties of different ethyl alcohol based secondary fluids with denaturing agents and methyl alcohol solution are summarized in table 3 presented below.

Table 3. Thermophysical properties of solutions with denaturing agents.

\begin{tabular}{lccccc}
\hline Sample & $\mathbf{T}\left({ }^{\mathbf{C}} \mathbf{C}\right)$ & $\varrho \mathbf{~}\left(\mathbf{k g} \cdot \mathbf{m}^{-3}\right)$ & $\mu(\mathbf{m P a} \cdot \mathbf{s})$ & $\mathbf{k}\left(\mathbf{W} \cdot \mathbf{m}^{-1} \cdot \mathbf{K}^{-1}\right)$ & $\mathbf{C p}\left(\mathbf{J} \cdot \mathbf{k g}^{-1} \cdot \mathbf{K}^{-1}\right)$ \\
\hline \hline EA20 & 30 & 959.75 & 1.75 & 0.5362 & 4450.41 \\
& 20 & 964.75 & 2.39 & 0.5039 & 4454.96 \\
10 & 968.45 & 3.46 & 0.4793 & 4432.63 \\
& 5 & 970.05 & 4.29 & 0.4657 & 4409.85 \\
& 0 & 971.65 & 5.47 & 0.4525 & 4378.51 \\
& -5 & 972.70 & 7.06 & 0.4369 & 4337.98 \\
& -8 & 973.33 & 8.45 & 0.4319 & 4309.00 \\
\hline \hline EA18+PA1.6+BA0.4 & 30 & 963.42 & 1.59 & 0.5581 & 4481.00 \\
& 20 & 968.42 & 2.10 & 0.5228 & 4481.40 \\
& 10 & 972.12 & 3.20 & 0.4950 & 4466.60 \\
& 5 & 973.72 & 3.95 & 0.4790 & 4452.75 \\
& 0 & 975.32 & 5.00 & 0.4642 & 4434.20 \\
& -5 & 976.37 & 6.51 & 0.4479 & 4410.65 \\
-8 & 977.00 & 7.76 & 0.4413 & 4394.00 \\
\hline \hline
\end{tabular}




\begin{tabular}{|c|c|c|c|c|c|}
\hline Sample (cont.) & $\mathrm{T}\left({ }^{\circ} \mathrm{C}\right)$ & $\varrho\left(\mathrm{kg} \cdot \mathrm{m}^{-3}\right)$ & $\mu(\mathrm{mPa} \cdot \mathrm{s})$ & $\mathrm{k}\left(\mathbf{W} \cdot \mathbf{m}^{-1} \cdot \mathbf{K}^{-1}\right)$ & $\mathrm{Cp}\left(\mathrm{J} \cdot \mathrm{kg}^{-1} \cdot \mathrm{K}^{-1}\right)$ \\
\hline \multirow[t]{7}{*}{ EA17.5+PA2+BA0.5 } & 30 & 963.62 & 1.52 & 0.4522 & 4560.71 \\
\hline & 20 & 968.62 & 2.05 & 0.4454 & 4573.60 \\
\hline & 10 & 972.32 & 3.16 & 0.4395 & 4564.75 \\
\hline & 5 & 973.92 & 3.93 & 0.4368 & 4548.50 \\
\hline & 0 & 975.52 & 4.99 & 0.4329 & 4522.39 \\
\hline & -5 & 976.57 & 7.24 & 0.4256 & 4484.98 \\
\hline & -8 & 977.20 & 8.16 & 0.4214 & 4456.48 \\
\hline \multirow[t]{7}{*}{ EA20+MEK2+MIBK0.5 } & 30 & 960.66 & 1.54 & 0.4466 & 4516.44 \\
\hline & 20 & 965.66 & 2.07 & 0.4332 & 4525.78 \\
\hline & 10 & 969.36 & 3.03 & 0.4317 & 4506.60 \\
\hline & 5 & 970.96 & 4.02 & 0.4299 & 4483.68 \\
\hline & 0 & 972.56 & 5.09 & 0.4278 & 4450.47 \\
\hline & -5 & 973.61 & 6.62 & 0.4246 & 4405.93 \\
\hline & -8 & 974.24 & 7.86 & 0.4166 & 4373.32 \\
\hline \multirow[t]{7}{*}{ EA20+MEK1.8+MIBK2.7 } & 30 & 955.20 & 1.64 & 0.4267 & 4506.42 \\
\hline & 20 & 960.20 & 2.27 & 0.4184 & 4525.78 \\
\hline & 10 & 963.90 & 3.47 & 0.4178 & 4506.60 \\
\hline & 5 & 965.50 & 4.34 & 0.4137 & 4483.68 \\
\hline & 0 & 967.10 & 5.51 & 0.4127 & 4450.47 \\
\hline & -5 & 968.15 & 7.24 & 0.4060 & 4405.93 \\
\hline & -8 & 968.78 & 8.65 & 0.4038 & 4373.32 \\
\hline \multirow[t]{7}{*}{ EA18+MA2 } & 30 & 962.39 & 1.50 & 0.4597 & 4510.09 \\
\hline & 20 & 967.39 & 2.02 & 0.4455 & 4513.65 \\
\hline & 10 & 971.09 & 3.06 & 0.4442 & 4495.18 \\
\hline & 5 & 972.69 & 3.77 & 0.4428 & 4475.45 \\
\hline & 0 & 974.29 & 4.75 & 0.4404 & 4447.55 \\
\hline & -5 & 975.34 & 6.18 & 0.4358 & 4410.58 \\
\hline & -10 & 975.97 & 7.52 & 0.4340 & 4383.68 \\
\hline \multirow[t]{8}{*}{ MA20 } & 30 & 960.12 & 1.25 & 0.4736 & 4341.67 \\
\hline & 20 & 964.02 & 1.59 & 0.4558 & 4322.28 \\
\hline & 10 & 967.12 & 2.16 & 0.4536 & 4286.07 \\
\hline & 5 & 968.37 & 2.57 & 0.4508 & 4260.01 \\
\hline & 0 & 969.62 & 3.12 & 0.4447 & 4227.76 \\
\hline & -5 & 970.52 & 3.89 & 0.4424 & 4188,66 \\
\hline & -10 & 971.42 & 4.87 & 0.4402 & 4161.65 \\
\hline & -13 & 971.62 & 5.66 & 0.4337 & 4142.07 \\
\hline
\end{tabular}




\section{CONCLUSION}

This study showed that the chemical character of various denaturing agents and concentrations can in a different way affect the thermophysical properties of commercial products found in Europa and the United States. As seen, the presence of two ketones had a strong effect on the freezing point. Methyl, propyl and n-butyl alcohols used as denaturing agents increased the density while methyl ethyl and methyl isobutyl ketones decreased the density values compared to pure EA20. Moreover, different denaturing agents were positively affecting the dynamic viscosity in most cases and EA18+MA2 had the lowest dynamic viscosity by up to $12 \%$. EA18+PA1.6+BA0.4, EA20+MEK2+MIBK0.5 and EA17.5+PA2+BA0.5 had as well lower dynamic viscosity than EA20 at the temperature of $-8{ }^{\circ} \mathrm{C}$ by up to $8.4 \%, 7 \%$, and $3.5 \%$ respectively. Only EA20+MEK1.8+MIBK2.7 had the dynamic viscosity higher by up to $2 \%$ compared to pure EA20.

As seen, different concentrations of propyl and n-butyl alcohol were affecting in different way the thermal conductivity and EA18+PA1.6+BA0.4 showed higher thermal conductivity than EA20. The presence of denaturing agents in form of ketones decreased the thermal conductivity in full temperature range. Methyl alcohol as denaturing agent was not increasing the thermal conductivity value and EA18+MA2 sample had almost the same thermal conductivity values compared to reference EA20 data.

EA17.5+PA2+BA0.5 had the highest specific heat capacity, by up to $2.5 \%$ than EA20 and by up to $1.5 \%$ than EA18+PA1.6+BA0.4. EA20+MEK2+MIBK0.5 and EA20+MEK1.8+MIBK2.7 showed very similar results and gave by up to $1.5 \%$ higher specific heat capacity. EA18+MA2 had higher specific heat capacity by up to $1.2 \%$ compared to EA20 and EA18+PA1.6+BA0.4 had higher specific heat capacity only in temperature range between -10 and $0{ }^{\circ} \mathrm{C}$ compared to ethyl alcohol samples with ketones and methyl alcohol, which is the most important operational temperature range for Swedish GSHPs.

Summing up, the commercial product commonly used in Sweden (EA18 + PA1.6 + BA0.4) showed the best thermophysical properties among different ethyl alcohol based products found in Europe when taking into consideration all thermophysical properties. Pure MA20 poses better thermophysical properties than EA18+MA2 and the lowest viscosity among all investigated alcohol blends. MA20 has as well good properties but special care needs to be taken due to high toxicity of methyl alcohol. Moreover, EA18+MA2 does not have good thermophysical properties compared to other ethyl alcohol blends and can be considered toxic. Thus, products containing small amounts of propyl and butyl alcohol or ketones are more recommended instead.

\section{ACKNOWLEDGMENTS}

The Swedish Energy Agency, Effsys Expand program and all industrial partners are gratefully acknowledged for financing this project.

\section{NOMENCLATURE}

$\begin{array}{ll}\mathrm{BA} & =\mathrm{n} \text {-butyl alcohol } \\ \mathrm{BHE} & =\text { Borehole Heat Exchanger } \\ \mathrm{c}_{\mathrm{p}} & =\text { specific heat capacity }\left(\mathrm{J} \cdot \mathrm{kg}^{-1} \cdot \mathrm{K}^{-1}\right) \\ \mathrm{EA} & =\text { ethyl alcohol } \\ \mathrm{GSHP} & =\text { Ground Source Heat Pump } \\ \mathrm{k} & =\text { thermal conductivity }\left(\mathrm{W} \cdot \mathrm{m}^{-1} \cdot \mathrm{K}^{-1}\right) \\ \mathrm{MA} & =\text { methyl alcohol } \\ \text { MEK } & =\text { methyl ethyl ketone } \\ \mathrm{MIBK} & =\text { methyl isobutyl ketone } \\ \mathrm{PA} & =\text { propyl alcohol } \\ \mathrm{T} & =\text { temperature }\left({ }^{\circ} \mathrm{C}\right)\end{array}$

$$
\begin{array}{lll}
\text { vol- } \% & =\text { volume concentration }(-) \\
\text { wt- } \% & =\text { weight concentration }(-) \\
\mu & =\text { dynamic viscosity }(\mathrm{mPa} \cdot \mathrm{s}) \\
\varrho & =\text { density }\left(\mathrm{kg} \cdot \mathrm{m}^{-3}\right)
\end{array}
$$

\section{Subscripts}

$$
\begin{aligned}
\text { exp } & =\text { experimental } \\
f & =\text { freezing } \\
r e f & =\text { reference } \\
t h & =\text { thermal }
\end{aligned}
$$




\section{REFERENCES}

Acuña J., Jansson J., Jernström T. 2015. The case of Sweden: market. Research, methods and IGSHPA Sweden. Proceeding of IGSHPA Technical Conference and Expo 2015, Kansas City, US.

Alcosuisse. 2014. Safety data sheet, Pumpetha 20vol-\%, Bern, Switzerland.

Altia Plc. 2012. Safety data sheet, Technical Ethanol: NATURET STRONG, GeoSafe, Rajamäki, Finland.

Antics M., Bertani R., Sanner B. 2016. Summary of EGC 2016 Country Update Reports on Geothermal Energy in Europe. European Geothermal Congress, Strasbourgh, France.

Bertolini D., Cassettari M., Salvetti G., Tombari E., Veronesi S. 1990. A differential calorimetric technique for heat capacity and thermal conductivity measurements of liquids, Review of Scientific Instruments, 61(1990): 2416.

Boyd T.L., Sifford A., Lund J.W. 2015. The United States of America Country Update 2015. World Geothermal Congress 2015, Melbourne, Australia.

EUR-Lex. Commission Implementing Regulation. 2013. (EU) No 162/2013 of 21 February 2013 amending the Annex to Regulation (EC) No 3199/93 on the mutual recognition of procedures for the complete denaturing of alcohol for the purposes of exemption from excise duty, Official Journal of European Union.

Gehlin S., Andersson O. 2016. Geothermal energy use, country update for Sweden, European Geothermal Congress, Strasbourg, France.

Government of Canada, Justice Laws - Consolidated Regulations. 2016. Denatured and specially denatured alcohol regulations (SOR/2005-22), Registration 2005-02-01.

Gustafsson A.M., Westerlund L., Hellström, G. 2010., CFD-modeling of natural convection in groundwater-filled borehole heat exchanger. Applied Thermal Engineering, 30: 683-691.

HelaChem Sweden AB. 2014. Safety data sheet, Köldbäraretanol 95\% (denaturerad med n-Butanol och IPA), Rosersberg, Sweden.

Henry B., Ignatowicz M., 2014. Investigation of thermophysical properties of ethanol based secondary fluids with additives used for ground source heat pumps, Report, Royal Institute of Technology, KTH, Stockholm, Sweden.

Ignatowicz M., Acũna J., Melinder Å., Palm B., 2015. Investigation of ethanol based secondary fluids with denaturing agents and other additives used for borehole beat exchangers, World Geothermal Congress 2015, Melbourne, Australia.

Ignatowicz M., Mazzotti W., Acũna J., Melinder Å., Palm B, 2016. Alternative alcohol blends as secondary fluids for ground source beat pumps, 12th IIR Gustav Lorentzen Conference on Natural Refrigerants. Edinburgh, UK.

Ignatowicz M., Melinder Å., Palm B., 2014. Evaluation of thermophysical properties of ethyl alcohol based secondary fluids, 11th IIR Gustav Lorentzen Conference on Natural Refrigerants, Hangzhou, China.

IGSHPA, International Ground Source Heat Pump Association. 2011. Ground Source Heat Pump Residential and Light Commercial - Design and Installation Guide, Oklahoma State University, Stillwater, Oklahoma.

Lide D.R., 1996-97. CRC Handbook of Chemistry and Physics, 77th ed.

Lyondell Chemical Company. 2003. Ethyl alcohol handbook, Equistar A Lyondell Company, 6th ed.

Melinder Å., 2007. Thermophysical Properties of Aqueous Solutions Used as Secondary Working Fluids, Doctoral thesis, Royal Institute of Technology, KTH, Stockholm, Sweden.

Melinder Å., 2010. Properties of Secondary Working Fluids for Indirect Systems, International Institute of Refrigeration, IIR, Paris.

NIST, NIST Standard Reference Database 23, Version 9.0, REFPROP Reference Fluid Thermodynamic and Transport Properties, Lemmon, E.W., Huber, L.M., McLinden M.O.

Peeters D., Leroy G., 1994. Small clusters between water and alcohols. Journal of Molecular Structure (Theochem) 314 (1994): 3947.

SGU, Sveriges Geologiska Undersökning: 2008. Att borra brunn för energi och vatten-en vägledning, Normförfarande vid utförande av vatten-och energibrunnar, NORMBRUNN-07.

Spitler J.D., April 2016. Types of commercial products used for GSHPS application in the United States, personal communication. 